DOI: 10.17707/AgricultForest.61.1.17

\author{
Aleksejs ZACEPINS, Valters BRUSBARDIS
}

\title{
PRECISION BEEKEEPING (PRECISION APICULTURE): RESEARCH NEEDS AND STATUS IN LATVIA
}

\begin{abstract}
SUMMARY
Application of information and communication technologies in various agricultural branches is done by using the Precision Agriculture methods and approaches. Beekeeping is old and traditional branch of agriculture where still many manual operations are done to care bee colonies and observe the apiary state and conditions. Information technologies can be used in the beekeeping to partly support the beekeepers by implementation of automatic or semi-automatic solutions for bee colony monitoring. Similar to Precision Agriculture also Precision Beekeeping (Precision Apiculture) is recently defined as an apiary management strategy based on the monitoring of individual bee colonies to minimize resource consumption and maximize the productivity of bees. International scientists and practical beekeepers started to support its development by implementation of various technical systems for automatic and real time bee apiary and colony monitoring.

Aim of this paper is to make summary of application of information technologies within beekeepers in Latvia, summarizing Precision Beekeeping development status and conclude about research needs and potential of its future development. To achieve above mentioned aim in cooperation with Latvian Beekeepers Association beekeepers survey is conducted. More than 400 beekeepers shared their thoughts and opinions about possible application of information and communication technologies for monitoring the bee colonies and upgrading the apiary management approach. Summary of conducted survey is described in the paper.

Keywords:Precision Apiculture, Precision Beekeeping, Apiary monitoring, Apiary management.
\end{abstract}

\section{INTRODUCTION}

Honey bee Apismellifera is one of the main pollinator insect. Bee role in agricultural crop pollination usually are irreplaceable (Warnke, 2009; Heard, 1999; Rader, Reilly, 2013). Latvia has long lasting traditions in beekeeping and maintenance of honey bees. Still it is one of the modern agricultural production

\footnotetext{
${ }^{1}$ Aleksejs ZACEPINS, (corresponding author: alzpostbox@gmail.com),1Faculty of Information Technologies, Latvia University of Agriculture, Jelgava, LATVIA, Valters BRUSBARDIS,Latvian Beekeepers Association, Jelgava, LATVIA.
}

Paper presented at the $5^{\text {th }}$ International Scientific Agricultural Symposium "AGROSYM 2014".

Notes: The authors declare that they have no conflicts of interest.Authorship Form signed online. 
branches. However in beekeeping compared to other modern agricultural industries many management operations are still carried out by hand work and it is hard to automate them, but there are potential for information technologies as well. Application of information and communication technologies in other agricultural branches is done by using the Precision Agriculture methods and approaches. Information technologies are successfully adapted in viticulture (Proffitt et al., 2006; Morais et al., 2008), in horticulture (Zhou et al., 2012) also precision forestry uses similar approaches (Kellndorfer et al., 2003; Zhang et al., 2011).

Similar to Precision Agriculture also Precision Beekeeping (PB) or Precision Apiculture is recently defined as an apiary management strategy based on the monitoring of individual bee colonies to minimize resource consumption and maximize the productivity of bees (Zacepins et al., 2015; Zacepins et al., 2012). Aim of Precision Beekeeping is to implement IT tools for colony remote monitoring. Several parameters of colony can be automatically monitored: temperature, weight, sound and others (Zacepins, Stalidzans, 2013).

International scientists and practical beekeepers started to support its development by implementation of various technical systems for automatic and real time bee apiary and colony monitoring. Several international scientific projects (for example, ITAPIC: http://www.itapic.eu; Swarmonitor: http://www.swarmonitor.comze.com; E-Ruche: http://www.e-ruche.fr) are started to improve the availability of practical tools and technical means for usage in Precision Beekeeping.

\section{MATERIAL AND METHODS}

Aim of this paper is to make summary of application of information technologies within beekeepers in Latvia, summarizing Precision Beekeeping development status and conclude about research needs and potential of its future development. To achieve above mentioned aim in cooperation with Latvian Beekeepers Association (LBA) beekeepers survey is conducted. 422 beekeepers shared their thoughts and opinions about possible application of information and communication technologies for monitoring the bee colonies and upgrading the apiary management approach.

To conclude about Precision Beekeeping status in Latvia beekeepers survey was conducted electronically using google forms during two month from February 2014 till April 2014. Link to the survey was published in LBA homepage (http://www.strops.lv) and LBA members were notified by e-mail. More than 422 respondents (beekeepers) completed the survey. Respondents were from different geographical locations, with different beekeeping experience and size of apiaries also differs.

Questions were divided into two groups, one group was about writing apiary diary (apiary book) and second group about Precision Beekeeping and application of information technologies for monitoring bee colonies in the apiary. 


\section{RESULTS AND DISCUSSION}

General characteristics and structure of the beekeeping branch in Latvia

Based on information provided by Latvian Agricultural data centre (http://pub.ldc.gov.lv/pub_stat.php) in Latvia there are 3211 beekeepers registered to the first of January of 2014, from them 2700 are LBA members, but total count of bee colonies is 85939 . Figure 1 shows number of beekeepers that are registered in Agricultural data centre public database (http://pub.ldc.gov.lv/pub_stat.php) and Figure 2 demonstrates count of registered bee colonies in period from year 2005 to year 2014. Observed tendency is that number of colonies is growing every year.

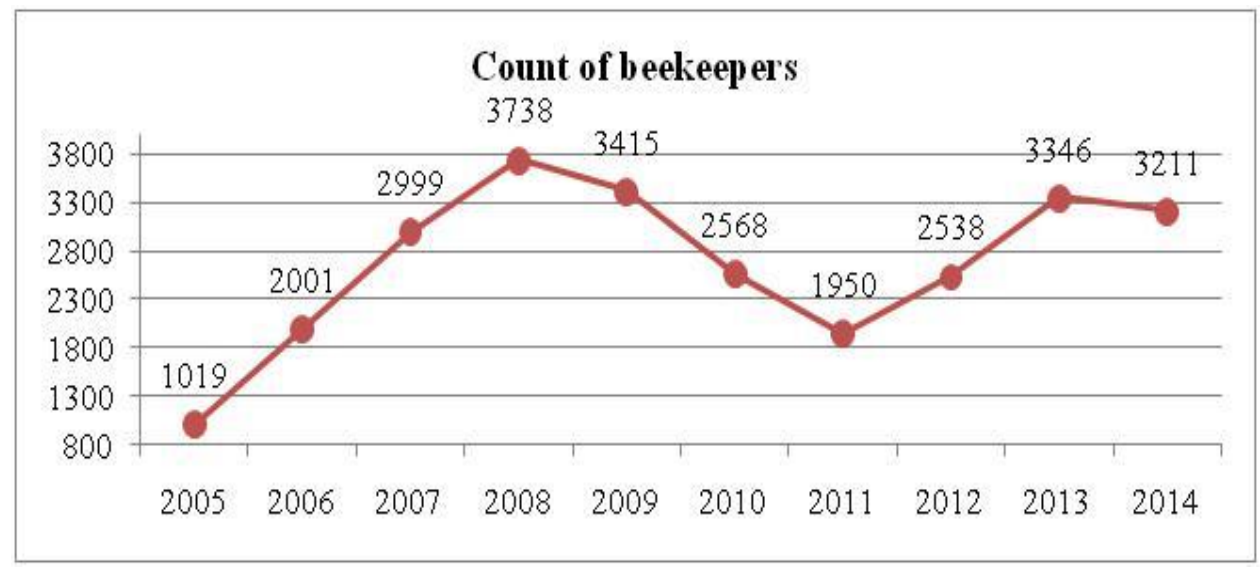

Figure 1.Count of registered beekeepers in Latvia

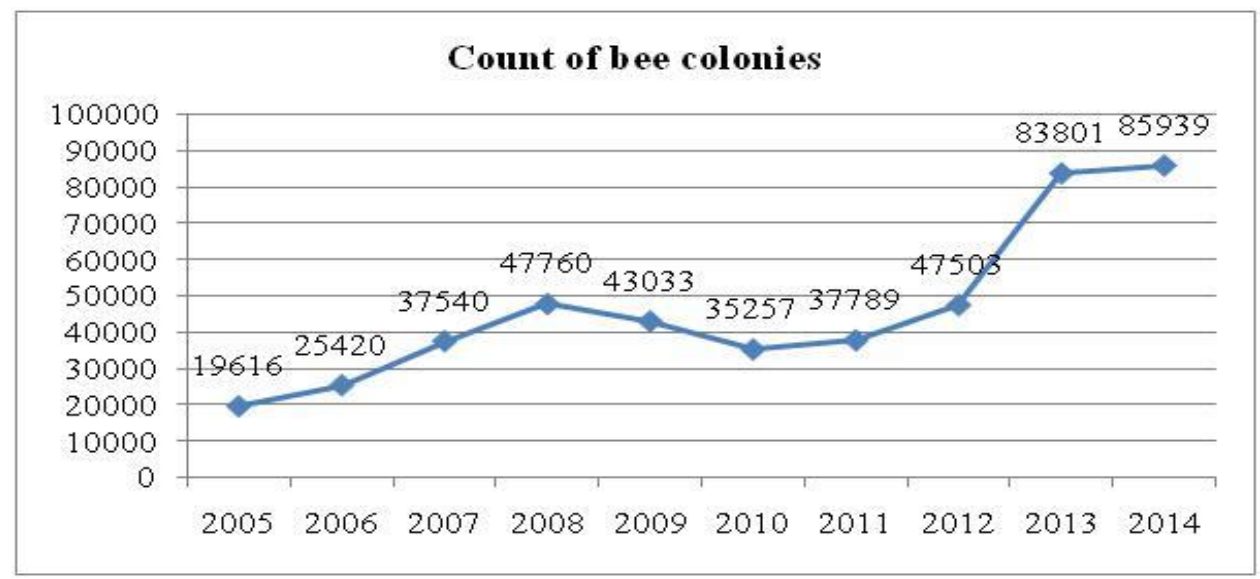

Figure 2.Count of registered bee colonies in Latvia

In Latvia there is no traditional beekeeping region, branch is well developed in all country territory. Real bee colony count for many years is in range from 60000 to 85000 colonies and this is far less than Latvian nature 
resources and forage potential allows, that means that beekeeping has potential for future development (Latvian Beekeepers Association, 2013).

LBA in year 2012 conducted a survey with aim to analyse a structure of the beekeeping branch (see Figure 3). More than 2500 questionaries' were sent to the beekeepers.

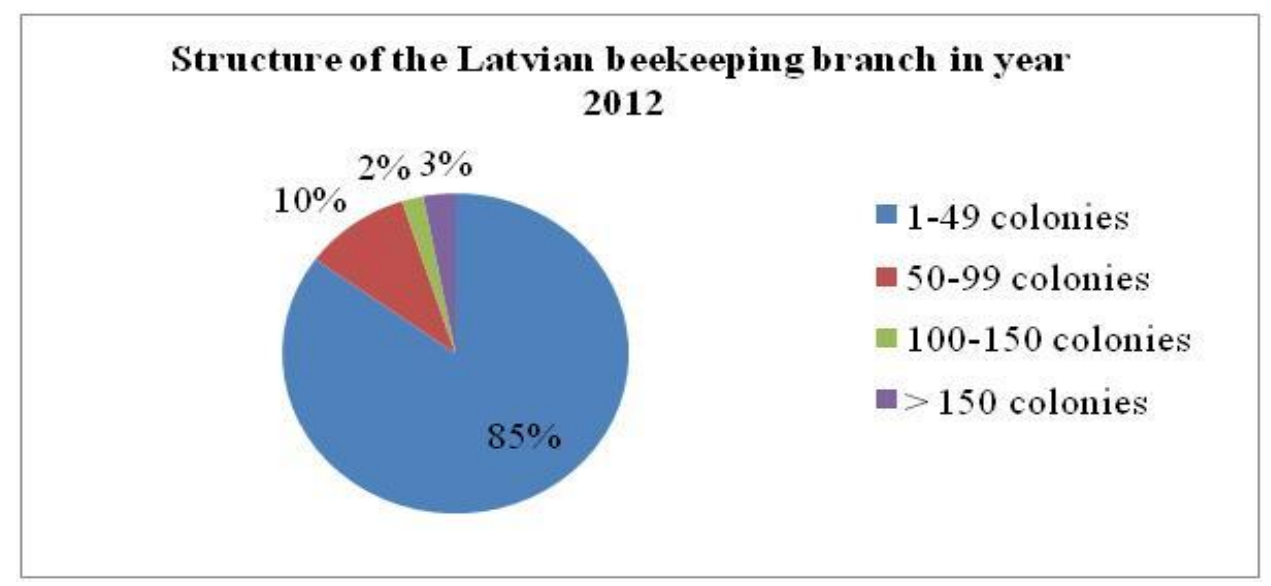

Figure 3.Structure of the Latvian beekeeping branch in year 2012

Statistical data proves, that still the big amount of beekeepers have only from 1 to 49 bee colonies, that means that beekeeping is organised very extensively and bee colonies are kept mainly as hobby and to generate low amount of additional family income. And primary this apiaries needs additional monitoring and care from state institutions and from LBA, because small apiary owners in many cases do not have good knowledge and experience about bee health and often this can cause that diseases starts to spread from such apiaries (Latvian Beekeepers Association, 2013).

Common feature of small European Nordic and Baltic countries is that there are low number of a big beekeeping production processing and commercial enterprises, that's why in beekeeping branch beekeepers and bee colonies are the main players.

Status of Precision Beekeeping in Latvia (analysis of the Beekeepers survey)

Despite the fact, that it is hard to imagine our life without information technologies and various IT devices, majority of respondents (77\%) answered that they organise apiary book in paper form and only $8 \%$ use PC for this purpose, $13 \%$ do not make apiary book at all and only 5 beekeepers use specialised software for writing apiary book with information about bee colonies. Mentioned software was: Bidata (http://bidata-win982000.software.informer.com/), Beetight (https://www.beetight.com), Hivenote, Bee 2 (http://bee2.eecs.berkeley.edu), Airbees (http://airbees.com) and local Latvian application ZM laboratory (http://ziedumedus.lv/). But answering the 
question "would you like to use specific, personalized application for apiary book?" majority (84\%) said "Yes". That means that beekeepers simply cannot find application, which would be suitable for their own needs. Respondents, who answered "no", stated, that it is not comfortable to use computational device (pad pc, smartphone) in the apiary, that their apiary is too small for implementation of computer-based solution or that their IT skills are not so advanced.

Then the respondents were asked to answer questions about Precision Beekeeping and usage of IT tools and solution for monitoring the colonies. Unfortunately only $21 \%$ of respondents heard or know this term and only $14 \%$ of respondents are using specific monitoring and IT tools to observe bee colonies. Main actions that beekeepers make to this moment are: visual observations of the bee colonies, control of the food limits in the colony, measuring temperature manually or by thermometers. Some beekeepers are controlling weight of the colony, some apiaries has one or two control hives equipped with specific scales for weight, temperature and humidity automated monitoring.

Afterwards respondents were introduced with fact that many scientific researches and efforts are done to implement Precision Beekeeping by developing and implementing various IT systems. And next question was about their readiness of implementation of some IT systems in own apiary. $72 \%$ of respondents would be ready to test IT tools in apiary, but $28 \%$ would not use IT at all. As comments, they stated that it would be very expensive, and it is needed to have a big apiary to start using automatic solutions for monitoring. There were also several beekeepers that are categorically against implementation of IT, saying that it would negatively affect the colony and honey production. Respondents, who are ready to try IT solutions stated that expenses of such system implementation should be 5-20 EUR per colony.

As the end, beekeepers mentioned some IT tools and programs which they would use in the apiary. Mentioned technologies were: bee queen finder in the hive, digital audio and video recorder and analyser, bee counter to analyse bee flight intensity, convenient automatic scales, automatic environmental parameter analyser to predict weather at the apiary, video monitoring inside the hive, hive vibration analyser, gps sensor.

\section{Future development perspectives of Precision Beekeeping in Latvia}

After survey it becomes clear that Latvian beekeepers do not have much information about Precision Beekeeping and available IT tools and technologies, which can be applied at the apiary for automation of colony monitoring. Mentioned IT tools mainly are already available at the market, but the price is not very appropriate for small apiaries. Majority of beekeepers, who know about available IT and automatic systems do not want to use them, because it is hard to change thinking and substitute traditional manual bee care methods with computerized approach. To solve mentioned issues it is needed to make different informative seminars and practical demonstrations of IT solutions to show the beekeepers the real working devices and systems. 
Actual thing for the Latvian beekeepers is to prevent remotely located hives from the theft and animal demolition, that's why video monitoring of the apiary and hive GPS systems were mentioned by the respondents, that means that such systems have chance to be implemented in Latvian apiaries.

Possible development perspective of PB in Latvia could be application of specific automatized wintering buildings for bee colony wintering during passive winter period. One big industrial beekeeping company are planning of building huge closed place for up to 1000 colony wintering. That building should maintain stable and comfortable microclimate conditions for bees, which can be achieved by using specific automatized climate control system.

One more direction of PB development can be sharing of information about apiaries between various beekeepers and developing a beekeeping map with main aim to prevent the spread of possible illnesses.

\section{CONCLUSIONS}

Latvian region has good conditions for beekeeping and application of Precision Beekeeping can be considered to improve the beekeeping practice and minimize the handwork.

To this moment Precision Beekeeping is not very common in Latvia, because it is lack of cheap, simple and reliable solutions for implementation of Precision Beekeeping. As well tested data analysis solutions for recognition of bee colony states and behavior not developed yet. System developers should concentrate on combination of various bee colony parameter measurement systems to provide whole picture of colony behavior.

For successful development and implementation of Precision Beekeeping it is needed to show to beekeepers clear added value of IT systems to prove that it can improve the beekeeping process and minimize the manual work for colony observations.

Based on beekeepers responds implementation of full cycle of Precision Beekeeping is valuable at average and big apiaries with at least 50 bee colonies.

\section{ACKNOWLEDGMENT}

Scientific research, publication and presentation are financed by the ERANET ICT-Agri Project „Application of Information Technologies in Precision Apiculture (ITAPIC)". Local agreement number is Z/13/1128.

Thanks to Latvian Beekeepers Association for help in conducting the survey and dissemination of information within Latvian beekeepers. As well, thanks to Latvian beekeepers for completing the survey and sharing their thoughts and ideas about Precision Beekeeping.

\section{REFERENCES}

Heard, T. (1999) The role of stingless bees in crop pollination. Annual Review of Entomology, Vol. 44(1), p. 183-206. 
Kellndorfer, J.M., Dobson, M.C., Vona, J.D., Clutter, M. (2003) Toward precision forestry: plot-level parameter retrieval for slash pine plantations with jplairsar. IEEE Transactions on Geoscience and Remote Sensing, Vol. 41(7), p. 1571-1582.

Latvian Beekeepers Association (2013) Latvian beekeeping program 2014-2016.20 p.

Morais, R., Fernandes, M. a., Matos, S.G., Serôdio, C., Ferreira, P.J.S.G., Reis, M.J.C.S. (2008) A ZigBee multi-powered wireless acquisition device for remote sensing applications in precision viticulture. Computers and Electronics in Agriculture, Vol. 62(2), p. 94-106.

Proffitt, T., Bramley, R., Lamb, D., Winter, E. (2006) Soil sensing in precision viticulture-A new era in vineyard management and wine production. Winetitle Ed, p. $51-55$.

Rader, R., Reilly, J. (2013) Native bees buffer the negative impact of climate warming on honey bee pollination of watermelon crops. Global change biology, Vol. 19(10), p. 3103-3110.

Warnke, U. (2009) Bees, birds and mankind.Destroying Nature by Electrosmog. A Brochure Series by the Competence Initiative for the Protection of Humanity, Environment and Democracy, p. 47.

Zacepins, A., Brusbardis, V., Meitalovs, J., Stalidzans, E. (2015) Challenges in the development of Precision Beekeeping. Biosystems Engineering, Vol. 130, p. 60-71.

Zacepins, A., Stalidzans, E. (2013) Information processing for remote recognition of the state of bee colonies and apiaries in precision beekeeping (apiculture). Biosystems and Information technology, Vol. 2(1), p. 6-10.

Zacepins, A., Stalidzans, E., Meitalovs, J. (2012) Application of information technologies in precision apiculture. In: Proceedings of the 13th International Conference on Precision Agriculture (ICPA 2012), Indianapolis, USA.

Zhang, Q., Li, J., Rong, J. (2011) Application of WSN in precision forestry. In: IEEE 2011 10th International Conference on Electronic Measurement \& Instruments, IEEE, p. 320-323.

Zhou, R., Damerow, L., Sun, Y., Blanke, M.M. (2012) Using colour features of cv. "Gala" apple fruits in an orchard in image processing to predict yield. Precision Agriculture, Vol. 13(5), p. 568-580. 